Review Article

\title{
A Review Development of Digital Library Resources at University Level
}

\author{
Agrey Kato $(\mathbb{D}$, Michael Kisangiri $(\mathbb{D}$, and Shubi Kaijage \\ The School of Computational and Communication Science and Engineering, \\ The Nelson Mandela African Institution of Science and Technology, P.O. Box 447, Arusha, Tanzania \\ Correspondence should be addressed to Agrey Kato; agreyk@nm-aist.ac.tz and Michael Kisangiri; kisangiri.michael@nm-aist.ac.tz
} Received 9 June 2020; Revised 28 January 2021; Accepted 5 February 2021; Published 16 February 2021

Academic Editor: Gwo-Jen Hwang

Copyright (c) 2021 Agrey Kato et al. This is an open access article distributed under the Creative Commons Attribution License, which permits unrestricted use, distribution, and reproduction in any medium, provided the original work is properly cited.

This study considered the development, awareness, adoption, and usage of digital library (DL) resources at the university level. To develop and implement a successful electronic library resource system, it is vital to review the success factors and identify the most important technological aspects of DL resources. Electronic library information technology was described and grouped into several categories that influence user satisfaction in a DL context. These are open access to information, the facility of access, uncomplicated interface design, high quality of the communication process, Internet performance, performance assurance service, ease of communication via social network, and patron-driven acquisition. With these important features of DL services, the simplicity of accessing online information and the performance of DL utilities have become of paramount importance. Several research works were therefore reviewed and evaluated to determine the usability of DL services; thereafter, the design of the DL discovery system was developed through Blacklight open-source software.

\section{Introduction}

The network is of great importance to libraries to tackle today's burning issues, such as knowledge overload, user diversity, and financial crunch, whereby digital service subscription depends on consortia broader access to digital services at a consequently lower cost $[1,2]$. The term electronic library resources define the information processed and digitally driven using hardware and software that offer information that can be accessed by digital electronic users through remote information provider networks or mounted locally by digital library (DL) managers. In reality, it transfers the citadel of historically getting information to a personalized, adaptable, and synergistic culture based on information, communication, and technology (ICT) [3]. Digital libraries are mainly designed to solve specific library problems. The online collection includes DL e-books, e-newsletters, e-references, theses, and dissertations [4]. The factors affecting user satisfaction in a DL context can be categorized as ease of access, few download exceptions, and limitations, simplicity of the DL interface design, quality of interaction process, Internet performance, quality assurance service, and ease in communication provided for by a social network $[5,6]$.

In terms of teaching, training, and studying, online academic libraries are important components of any university's information infrastructure [7]. The development of DL resources is as a result of the need for people to keep their history, discoveries, and achievements records and collections [8]. Academic institutions, through their library departments, make major investments for DL resources in the area of subscription fees, information management systems, awareness, and marketing of DL resources to ensure clients are aware of the available tools and are actively using them [9]. Therefore, library users must know their information needs and make maximum use of the provided DL resources to appreciate the value of investments made by their libraries. It is not enough for academic institutions to raise students' awareness about the use of DL tools; it is now in this context that researchers are working to improve the understanding, availability, and use of DL. According to some studies, the knowledge and use of DL around the world 
have revealed a range of barriers preventing learners from using online library resources [10-12].

Libraries worldwide are quickly transforming due to the ongoing growth and application of ICT [13]. It is important to note that while the barriers to accessing DL resources may be similar in different universities, there are more in developing countries than in developed ones. The notable obstacles in literature are poor information and digital literacy skills, students' negative attitudes towards electronic tools, poor Internet connectivity, poor ICT infrastructure, information overload, vast amounts of irrelevant information, licensing limitations on access to the DL collection, lack of generic e-resource portal interfaces, preference for print assets over electronic resources, discouraging e-resource use by academic staff, user authentication, download delay, lack of comprehensive ICT and searching skills among library staff, high cost of affordable online access, and low organizational budget for library departments [14-17].

Most library users prefer popular web search engines to library-driven systems; consequently, most library services continue to be underused. Librarians, therefore, need to adjust what they learn, how they function, and their effectiveness [18]. Nonetheless, the absence of training for staff and other library users is a limiting factor in the accessibility and use of e-resources as users face difficulties in assessing services and the staff may lack adequate expertise to assist the users [19]. Among the e-library manager's obstacles is that the development of a DL requires substantial investment in capital, technology, and manpower to satisfy users. Therefore, library culture has a history of resource sharing due to budget constraints that most libraries face. A library organization embraces a common goal of resource sharing and cooperation, commonly referred to as a consortium. This study is an attempt to assess the awareness, utilization, and development of electronic resources in the library by the academic community of universities. Therefore, this paper represents a critical review of DL resources taking into account the practical aspects of library services. The paper defines the criteria used in creating a DL for the universitylevel research community. Hence, this paper aims to review and evaluate some research works and thus determine the usability of DL services and develop a user-friendly DL discovery system to mitigate these learners' technical hitches. Therefore, this paper reviews DL resources in the area of usability, DL development as well as ease of accessibility, and finally developed DL discovery systems.

\section{The Quality of Service in Digital Libraries}

With the advent of DL services, the quality of service (QoS) has become crucial in assessing the efficacy of service delivery. Diverse models and structures have been suggested to analyze the QoS in DL systems [20]. Nevertheless, the prevalent concentration of work in QoS for the DL is about the extent of the user experience perspective. Ahmad and Abawajy [20] addressed different dimensions that are from the perspective of digital service providers. The model shows that the level of QoS provided by digital service providers directly affects the perception and satisfaction of end-users.
The other hypothesis of the design of electronic libraries was suggested by DeLone and McLean [21] to investigate how the reliability of the process and data provided affected the satisfaction of users. Wixom and Todd [22] also established that information and device reliability, perceived utility, ease of use, and application behavior of data storage systems affect user satisfaction. Moreover, the work by Zhang [23] indicates that the system and quality of information are key determinants of the happiness and sense of community of social networking users. Tu and Hwang [24] addressed the role of sensing technologies and learning strategies in library-associated mobile learning. The study aimed at investigating issues like the type of sensing or location-based technologies and learning strategies employed in library-supported mobile learning. The results showed that advancement and popularity of mobile, wireless network, and sensing technologies have further provided a more convenient and effective environment for accessing library facilities and resources.

A study conducted at the University of Houston Libraries by Guajardo et al. [25] conveyed the evolution of discovery systems in academic libraries. The authors concluded that, for several years, libraries have adopted discovery systems to provide search experiences that reflect user expectations and improve access to e-resources. The University of Houston Libraries has kept pace with this evolving trend by pursuing other discovery options which include an open-source tool, a federated search product, and a two-index-based discovery system. The important criteria for assessing discovery systems and valuable lessons that may be applied in future system-evaluation processes and implementations should be identified in pursuit of better options for users and improved access to e-resources. A recent study by $\mathrm{Oh}$ and Colón-Aguirre [26] on the perceptions for use of Google Scholar and academic library discovery systems reveals that the perceived comprehensiveness, subjective norm, loyalty, and intended use of academic library discovery systems are higher than Google scholar, while at the same time, the perceived ease of use, satisfaction, and system quality of Google Scholar were higher than those of academic library discovery systems, implying that users' satisfaction with the DL is the key indicator for the quality of DL services.

\section{The Satisfaction of Users with Digital Library Systems}

User satisfaction assessment and preservation is an essential part of library quality management. Within the DL background, satisfaction refers to "feeling happy with the DL in helping to complete a task" [27]. Consumers' DL satisfaction is closely linked to their experience with DL services. Identifying the typical standards of DL providers requires (i) comprehensiveness, including everything; (ii) accessibility, everything available immediately; (iii) instant-gratification, response speed; (iv) software capacity, seamless; (v) userfriendliness, single interface; and (vi) various formats, wording, images, and audio [28]. On the other hand, when 
assessing DL, user satisfaction focusing on the interface and functionality offered by the DL is very important [13].

3.1. Information Quality. Several academicians and researchers have recognized the importance of data reliability as a key component in the analysis of an effective computerbased data system. Information quality is essential in DL's point of view to support information needs. As a result, its attributes are usually associated with consistency, design, timeliness, currency, reliability, completeness, accuracy, and significance [29]. Therefore, the quality of information significantly affects the satisfaction of DL users.

3.2. System Quality. System quality affects the perception of users of the performance of a DL in knowledge assortment and delivery [29]. In the development of information systems, the quality cycle of the systems is a strong determinant for user satisfaction in various contexts. Accessibility, accuracy, reliability, and quality are the key attributes of DLs performance measurement systems [29-32]. Quality, accessibility, and consistency ensure the DL requires remote access to the infrastructure to access information wherever and whenever. This also ensures that the DL is accurate and functionally usable over time. When using the DL to search for information, effectiveness is associated with the quality, accuracy, and completeness of users. Considering the findings of Masrek and Gaskin [13], the quality performance of the DL's software dramatically affects satisfaction; hence, Figure 1 is formulated to show that the quality of the system predicts users' satisfaction with the DL significantly.

3.3. Service Quality. User perception of the performance of a DL in the processing and distribution of information is characterized by service quality. As with information quality and applications, earlier studies show strong support for the contribution of the QoS to user satisfaction with DL. Different service quality models have been developed by scholars to test the DL. For example, DigiQUAL's [33] and LibEval [29] designs are available. Other authors investigated DL service quality attributes or measurements in addition to these models [32]. One of the prominent qualities of digital service performance is accession, reliability, accessibility, and responsiveness. Digital library's service quality factor is very important as there is no face-to-face interaction in digital communication. For an open, healthy, sensitive, and wellintegrated DL, there should be a favorable user satisfaction score and it can be concluded that the QoS and reliability have a big impact on user satisfaction with DL.

3.4. Perceived Usefulness. Perceived usefulness is described as the degree to which a person perceives that using DL improves academic performance [34]. Some authors have adapted products used by researchers to measure the perceived value by operationalizing the individual net benefit of DL services and incorporating information system success model (ISSM) into the Technology Acceptance Model (TAM) [31, 35] Several studies have shown that perceived

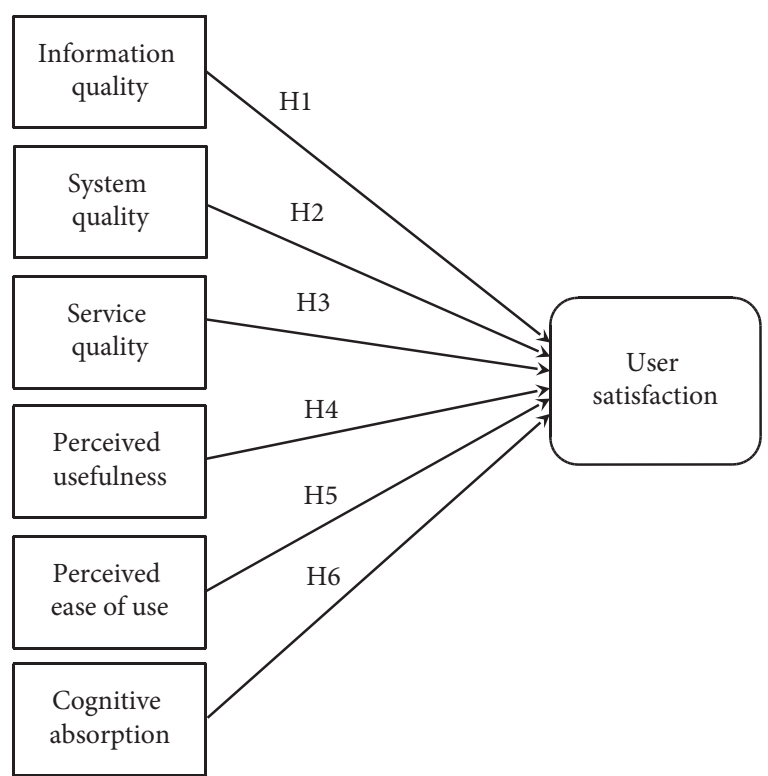

FIgURe 1: Users' satisfaction with digital libraries [13].

usefulness influences the acceptance of DLs by users $[18,36-38]$. Other studies have however shown that the perceived value is a strong indicator of satisfaction $[39,40]$. Users of DL need information and are searching for it. However, their satisfaction levels can be lowered if their experience of using DL-provided knowledge is not useful or beneficial.

3.5. Perceived Ease of Use. The perceived ease of use is defined as "the degree to which an individual believes that it would be effortless to use a particular system" [34]. In this context, user-friendliness indicates a belief that using DL would require minimal effort. Literature also indicates that accessibility is sometimes related to ease of use [41]. Where it is difficult to access a DL, users tend to consider it difficult to use and on the other hand, users are more likely to see it as user-friendly when it is readily available [42]. Other library researchers found that online public access catalog (OPAC) satisfaction was related to ease of use [43]. Based on these findings, the perceived ease of use is thought to have a positive effect on satisfaction. To this end, it is assumed that user-friendliness significantly increases user satisfaction with the DL.

3.6. Cognitive Absorption. The concept of cognitive absorption denotes the deep involvement or holistic interaction with the DL of a person. This concept was first introduced into the information system (IS) studies, to help users evaluate such systems. The first concept incorporated the facility of use as one of the building's dimensions [44]. Nevertheless, mental retention was used in the modified and improved model as determinants of user-friendliness [13]. No one has ever tried to examine the effect of cognitive focus in the sense of DL on satisfaction. Since the DL is a subset of computer-based ISs, its functionality is somewhat close to 
other forms of IS such as e-learning. Therefore, results on the effect of cognitive integration on the satisfaction of users from previous research should also be important for DLs. With this rationale, the cognitive absorption greatly increases user satisfaction with DL.

3.7. Patron Driven Acquisition. The satisfaction of users with digital libraries from the above-mentioned variables is patron-driven acquisition (PDA) or demand-driven acquisition (DDA) and is a library development model in which libraries purchase materials only if it is clear that a patron requires it. Libraries provide DL users with access to search engines, educational resources, and/or library catalogs in an appropriate manner from which the client can request items. When certain thresholds such as the number of pages read or several requests are reached for an item, a library purchases the item and provides instant access to patrons [45]. The library may obtain the resource indefinitely, or acquire a license to use the resource only at certain times or in some way. Since the material purchased is in digital format, "PDA emphasizes collecting for and at the time of need" rather than gathering long-term focus [46]. The patron-driven acquisition is often associated with e-book sets, although there are also choices for print and hybrid PDA [47]. Focusing this approach on the use of digital content PDA has several advantages. For instance, distribution is instantaneous; e-books do not need any physical space to manage, improving the capacity of the collection; and purchases are assured, which is an important consideration when purchasing materials [45]. Furthermore, security is integrated into the system to avoid the decimation of library budgets by library staff without intervention. However, users can print only a few pages at once, certain publishers do not write book pages, and e-books can be "checked-out" for a certain time. Many patrons are not allowed to access a title until it is "checked-in." At the same time, patrons may not want certain books from their publishers or third-party vendors to sell any specific titles in electronic format and many vendors do not allow e-book downloads [48]. Others do not allow individual chapters or entire e-books to be downloaded.

Comparing shopping among e-book vendors is not easy unless a library deals with more than one vendor. It may be difficult for software subscribers to view e-books to please users, library budgets may be inconsistent year after year, e-books may be more expensive than printed books, and retailers prefer to charge extra for digital versions of books. Project counter statistics vary from seller to seller; thus, statistics are important for evaluating the use and reasoning of e-book maintenance, including the reliability of specific counter statistics and DL Resource Administrators' access capabilities, and are challenged to take notes or annotate e-book text between sellers, faculty, and students. This is the main complaint of students concerning their experience in one- or multi-seat licenses of e-books and e-book titles [49]. Libraries do not deal with online book theft when dealing with PDA; they are concerned about broken Internet links that lead users to e-books. Nevertheless, once publishers are aware of this problem, they can easily fix them. Libraries can accommodate on- and off-campus use of e-books, making them accessible anywhere. E-book PDA is a new tool for integrating library practices, and e-books provide libraries and consumers with unique advantages in some cases, such as saving storage and being immediately available [50]. Table 1 summarizes the essential variables related to DL adoption and usage.

\section{Technological Design Aspects of Digital Library Resources}

Technological aspects of designing DL resources concentrate on the following elements: ease of access, interface design, communication level, device reliability, and QoS [64]. Digital library resources variables are identified as the technical tools required for developing a DL for the research community and digital services based on the theoretical model, updated documents, and DL initiatives around the world [65].

4.1. Digital Library Resources. This is the digitization of all records in the DL collection. While journals already held by the library with a digital subscription are not considered to be part of this collection, the references are provided to the reported catalog. The digitization of documents created by the library and information studies of the research community is preferred since the goal is to integrate some of the features of the semantics DL; a room is given for sharing and collaboration in the writing of user-generated content. DL resources involve researchers' works as well as online records including monographs, educational event promotional posters, online images, workshops, symposia, or colloquia, and visiting interviews with researchers.

4.1.1. Technological Tools. The Open Source Software eXtensible Catalog (XC) is one of the basic technology tools applied based on an analysis in the need to create linguistic features in DLs [66]. This technology comprises a metadata scheme for the functional requirements of RDA (Resource Description and Access) and FRBR (Bibliographic Record). When XC's metadata scheme is ready to present information in RDA, a semantics DL can be created. The inclusion of a repository in the DL is considered so that information on advances in research studies and on the success of these can be held with their tutors. The repository is considered to be an extension to the DL and use the virtual library to (i) establish collaborative and educational communication and (ii) favor the preceding electronic release of the interim and final study results, but the tasks are limited to obtaining these resources for downloading and consultation.

There are several tools available to create useful content; such tools are (a) weblog technology (blogware), content management systems, specifically designed for blogging, (b) blogging tools, including readers, moderators, PDF-saving services, backups, labeling, scanning, reporting, dynamic optimization and indexing, and a wide range of blog-enhancing applications, (c) social networks, to promote 
TABLE 1: A summary of the essential variables related to digital library adoption and usage.

\begin{tabular}{|c|c|}
\hline Author(s) & Factors \\
\hline $\mathrm{u}[43]$ & Perceived usefulness and user-frie \\
\hline Chengalur-Smith & $\begin{array}{c}\text { Basic software literacy and DL comfort, technology attitudes and computer anxiety, self-efficacy, accessibility, } \\
\text { quality, and reliability }\end{array}$ \\
\hline Joo and Choi [52] & Behavioral purpose in educational library eny \\
\hline Gojeh et al. [53] & $\begin{array}{c}\text { Human and physical environmental factors which affect DL usage and information services in schools in } \\
\text { Nigeria }\end{array}$ \\
\hline $\mathrm{Hu}$ & $\begin{array}{l}\text { Information services and collection services, and indivi } \\
\text { perception, whilst data organization services indirectly } \\
\text { services and indivi }\end{array}$ \\
\hline Thur & $\begin{array}{r}\text { Research data management (RDM), the fun } \\
\text { RDM operations, and the }\end{array}$ \\
\hline Isah & Technology acceptance, reaso \\
\hline & \\
\hline Xie & if \\
\hline Ow & The need to use DL services, strong preference for \\
\hline Kos & The expectation of performance, \\
\hline & $\log y$ \\
\hline $\mathrm{Kad}$ & Collection a \\
\hline Mte & $\begin{array}{r}\text { Poor institutional ICT infrastructure, limited e } \\
\text { knov }\end{array}$ \\
\hline
\end{tabular}

communication amongst the community, (d) content management systems (CMS) which makes it possible to modify data from any computer connected to the Internet, making it easier to build, distribute, view, and preserve web content, and usually provide a what you see is what you get (WYSIWYG) text editor that allows the user to see the result when writing without thinking about programming codes, (e) Wikis that is a tool for modifying, improving, or enriching content published by another person, and (f) digital word processors and spreadsheets which are words/ tools that can be retrieved from any Internet-connected computer to process platform numbers online [67]. Via these applications, users can access, edit, reformat, and share documents. One of the advantages of this technology is the possibility of producing content in a cooperative and collaborative style [68]. Multiple users can also modify the text at the same time, keeping their modifications historically registered. The system has platforms for digital and multimedia storage, publishing, sharing, and editing (photo, audio, and video) to simplify access, organization, and search. In addition to finding some places where the client can publish files, they can find several tools for sharing and spreading information on the DL resource. The archive should be a forum that allows students and scholars to pick, compile, and store alumni work and various academic materials, making the Onix program suitable for monograph marking. This program uses the XML language, widely used for data exchange or sharing by multiple applications and platforms [69]. It is acceptable that the use of XML has many benefits, such as design continuity and data transferability to other systems [70].

4.1.2. What Next in Digital Library Services. In librarianship and information research, DL systems have a direct relation with digital publishing. Tripathi and Jeevan [71] reviewed the quality of metadata, semantic search, recovery, and browsing assessment while investigating the quality assurance services in distance learning libraries. Services suggested by users and library managers are mobile information services, resourceincreasing programs, group annotations, tagging, and the highest number of consultations. The mobile information services should also include Simple Syndication (RSS) and electronic media notification services. The other component that is recommended is social network communication, which enables users to communicate with their library [72]. The proposed DL service is outlined in Figure 2.

4.1.3. Copyright Issues. Academic librarians have complex barriers and problems in managing the copyright process of the labyrinth. Some of the issues are evident, but others, especially in a digital environment, are much more subtle. Issues that cause confusion and concern about copyright law's applicability include e-reserves, registration, delivery, and equal use of information. The role of academic libraries is to offer access to information to their constituents anywhere and at any time [73].

Digital library creators and their materials, i.e., digitalborn, digital turned, and acquired digital, should preserve copyright issues in the production and management of digital libraries in a legal framework to address copyright issues and protect the rights of content creators and owners. It would be a good idea to consider technical protection measures such as e-watermarking, digital signatures, authentication, etc. since DL are in the process of creating digitally born content to regulate infringement in the digital environment. In the current era of open access (OA) where information is made freely available to users, content producers should be worried about the infringement of copyrights. In addition to uploading digitized content on websites, libraries are digitizing to protect old, fragile documents and posterity. The DL is under contract or has been given licenses to use this 


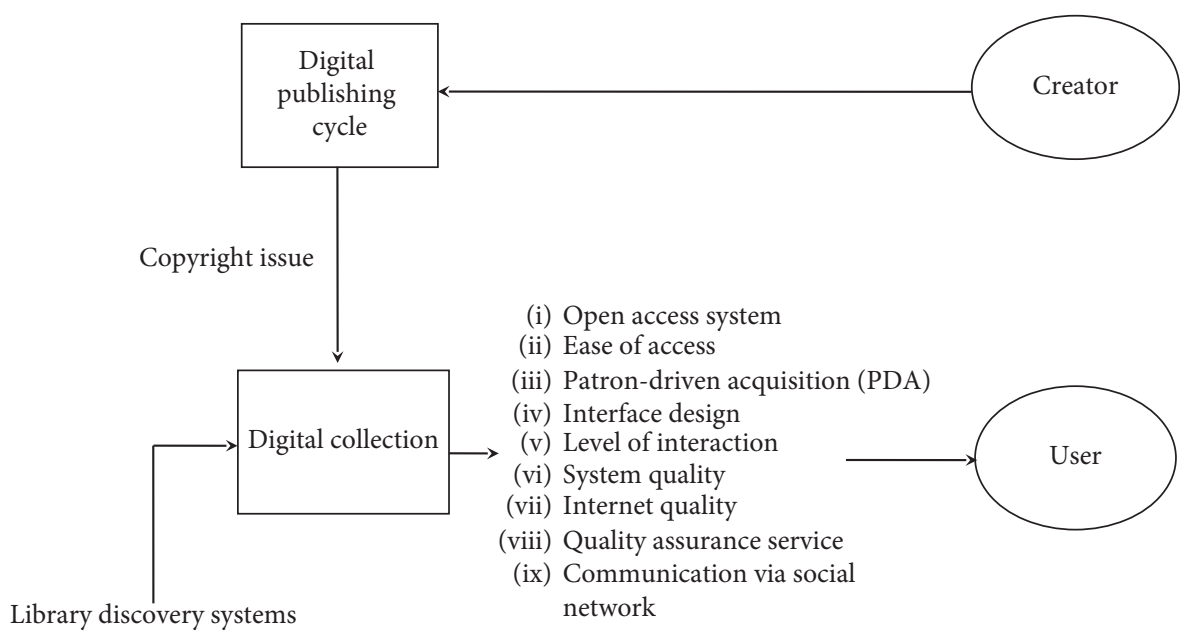

Figure 2: Proposed design of digital library services.

material for digital content. Based on the license terms and conditions, the DL must sensitize and notify users, so that there is no total copyright infringement and a strong obligation to comply with the contract terms and conditions. Many owners of digital media copyright are found to rely on technological mechanisms to regulate access to digital files and recycle works. Since technology can provide protection systems, it also has the potential to create systems that can bypass this kind of protection [74]. Some of the rights management functions of computer systems could include tracking, identifying, and authenticating users, providing the copyright status of each digital object and limiting its use or charges, handling user transactions by only allowing access to not so many copies, or charging for copies, or transmitting requests to publishers [75].

4.1.4. Library Discovery Systems. The library discovery system has many definitions and is now described as DL technology that enables a library user to simultaneously search for multiple web-based resources and produce accessible search results. Digital library discovery systems are becoming the leading technology allowing users to explore and access university and academic library information resources. Nonetheless, little research has been done to examine the use and impact of DL discovery systems. Evidence supports the initial claim of discovery system developers that the one-search box approach adopted by Google and other Internet search engines is a suitable method for designing library catalogs. Discovery system users, on the other hand, strongly enjoy the simplicity of conventional library tasks over attempts to place the catalog within the conceptual framework of social media [76].

A short description of the Resource Discovery Services (RDS) function, the single discovery search tool revolutionizes the entire library experience. Users often had to search individual resources including OPAC, databases, collections such as e-book sites, or collections of newspapers manually before RDS to find relevant information on a topic.
This was a time-consuming and sometimes labor-intensive process because databases sometimes work differently, i.e., with different managed vocabulary, etc. By offering a onestop shop, library discovery tools change how users can search for academic resources. Google-like search engines have changed the way users search for information on educational tools significantly [77]. It is important to understand their role and impact is growing given the increasing prevalence of RDS or Web Discovery Systems (WDS). They represent a significant investment in the organization and must be seen to add value to the library's position in the organization. In the past, it was supposed to check for databases (or full text) and then followed links to the full text but since it was impossible to find everything through one vendor's access, users could either visit each in turn or use a federated search in one step to scan vendor product groups (and then link).

The DL discovery system is special because it maintains an index reflecting the full-text content that can be searched for, as well as providing a link facility for accessing the fulltext content. The benefits of discovery service tools are that they provide access to a large amount of variable material, they are quick as searching is in local or centralized indexes (although they are huge), they focus primarily on full digital text, and they are easy to use [78]. The central Primo and Primo, EBSCO Exploration Service, Summon, and World Cat Discovery are some of the index-based exploration resources that are commercially available. The open-source software includes Blacklight, VuFind, eXtensible database, and Franklin with no index-based discovery services. Unlike the commercial discovery software mentioned above, they are not able to search in OA and do not include a community-created central index [79]. Despite its capability and relative ease of use, there exist drawbacks associated with the library discovery system. For instance, there will always be some inaccessible items to discovery tools unless all content providers share their contents. Some library-subscribed databases may not be compatible with some discovery tools. In this case, researchers should be informed and advised appropriately. 
One major problem with the discovery method is that many repositories use technical language to provide topic access to the materials they contain. Since this method effectively combines several databases, researchers must be aware that databases may identify a particular topic differently [79, 80].

4.1.5. Digital Library Discovery System Supporting Works. Sarkar and Mukhopadhyay [81] discussed the design of an open-source software-based library discovery system for full-text ETD retrieval based on a cataloging framework developed using available global standards and best practices in the domain of these cataloging. The prototype framework provides a single-window search and retrieval system for end-users for discovering ETD at the metadata level and fulltext level. This prototype framework is based on a three-layer architecture with Koha ILS as a backend metadata provider, Apache-Tika as a full-text extractor, and VuFind as a discovery system. A MARC-21 bibliographic format that is specifically designed to handle TDs is used as a data handler mechanism in Koha ILS and the harvester of VuFind is tuned to fetch bibliographic data related to ETD in marcxml format. The user interface of VuFind is also configured to support accessing ETDs from global-scale services like NDLTD, OATD, IndCat, ShodhGanga, etc., apart from the local level ETD collection to provide an all-in-one search interface for users but it lacks the advanced query.

Roy et al. [82] developed a web-scale discovery system using different open-source software (OSS) and open standards. Although the study was not based on real-life examples or demonstrations of discovery tools, the tool has been tested on several configurations. It is a prototype resource discovery framework that may be integrated with any Web-enabled online information retrieval (IR) system. The present review shares tested experiences of integrating Koha (here open-source integrated library system (ILS)) and DSpace (open-source repository system) with VuFind (open-source discovery tool) along with other external, commercial, licensed, unlicensed, or open access databases.

A recent work by $\mathrm{Pal}$ [83] provides an outline of the library resource discovery environment and explains how technologies, methodologies, and products can adapt to changes in the evolving landscape of information in scholarly communications. The author also attempts to evaluate comparative features of library resources discovery products and services available in commercial and opensource discovery systems and so does the case study of the adaptation of library resources discovery tools in Central Library, Tripura University. The work conducted by Beyene and Ferati [84] shows that even though such a "Google-like" experience is praised as beneficial to users, problems of accessibility and usability related to the diversity of needs, goals, preferences, and needs of users still exist. To better comprehend these problems, the authors extensively reviewed literature and primarily clustered issues into navigation, interface, and resource-description categories. In this context, adaptation was proposed as another method of enhancing RDT accessibility and usability and could be performed at the levels of interface, information, and navigation. In general, the authors showed how adaptation could be considered to alleviate the problems of usability and accessibility of RDT interfaces.

Chetan [79] availed an outline of discovery tools that are an extension of the $3^{\text {rd }}$ generation library catalogs. In their work, the author deliberated the features related to opensource and commercial discovery systems. The challenges associated with these systems were identified to be related to metadata, standards adoption, and recommended practices. The author also proposed comprehensive index coverage, creation of open access index, cooperation of discovery system agencies, and vocabulary standardization as initiatives to address these and other challenges. The study concluded that there is need for additional open-source solutions in the discovery system to reduce the costs which are controlled by commercial enterprises. This is because contemporary resource discovery tools allow for facet-rich interfaces that offer a variety of alternatives that can reveal resources to their potential users and support their navigation.

Chickering and Yang [85] evaluated thirteen major discovery tools; among them, three were open-source and ten were proprietary tools, bench-marking sixteen criteria recognized as the advanced features of a next-generation catalog, while some have been used in previous research on discovery tools. The study compared all the major discovery tools with the overall findings and recommendations that discovery systems should be integrated with social networking sites and persistent links, and the systems should serve to update librarians on the latest developments and assist them in their adoption. Beyene [86] examined one of these tools in the context of universal access and the utilization experience of users with print disabilities. The study explored the barriers that print-hindered users face while using library search tools, and what could be done to device discovery tools that integrate the needs of users with print disabilities. The data obtained was used to forward-design recommendations for future action. The study generally revealed that print-disabled users preferred that RDTs should offer them simplicity of use and features that capture and focus on their preferences and needs to avail adaptations related to content presentation and display.

4.1.6. Open Access Initiatives and Adoption. Open access to information is a generic term used for information tools made available for large-scale commercial or corporate use in the public domain, regardless of subscription fees or access fees [87]. Open access facilitators and users need to create an online link for the dissemination of information. The OA movement uses the term Gold OA for OA provided by publishers, and Green OA for OA provided by libraries while work that is not OA or accessible only at a fee is called Toll Access [88]. Thus, all kinds of OA remove price barriers and are termed as Gratis OA, as opposed to Libre OA if at least some permission barrier is removed as well.

The other kind of OA is academic OA journals which are a kind of web-accessible online journal without access restrictions, such as annual subscription fees. Therefore, the owners of the OA systems not only provide free access to academic material but also have to provide other rights 
packages for research literature producers and consumers. In the past, there was no freedom to publish, store, recycle, and reconstruct the academic content by normal copyright protection procedures. Due to this, the copyright laws of most countries had prohibited the free distribution or re-use of educational content. At the present, expanding the freedom to distribute or reuse published contents via an alternative to copyright protection mechanisms, such as Creative Commons or Copyleft licenses, users are nowadays pleased to use these community resources for further information production and distribution. While preserving creators' interests, creative commons licenses also harness the full potential of OA research literature [89].

Palmer et al. [90], who emphasize the role of librarians in $\mathrm{OA}$, established that the American Academic Libraries have a positive attitude towards OA ideals and focus on promoting it. According to research conducted at private universities in Nigeria, by Bolarinwa and Utulu [91], academic librarians have shown a positive view of the OA information tools. The work done by Lwoga and Questier [92] revealed that about $75 \%$ of librarians had strongly supported OA topics on campus. The study suggested that the librarians can further support OA through the following: (i) providing enhanced access to OA works by linking OA works via library catalogs, including researchers' OA resources and Selective Information Dissemination (SDI) services, making them part of a federated search, (ii) publishing OA works; many research organizations have inhouse publications that can be called OA, which host the journal through open journal's systems and libraries can take steps to publish and identify potential outlets for publishing activities in different campus environments, ranging from newsletters to special collections and resources for students, (iii) digitize OA versions of non-copyrighted works, and (iv) initiate the October OA Week each year to mark the International OA Week which can include a variety of activities such as setting up talks, awarding researchers, and directing researchers on new developments in the field [93].

One of the techniques of OA is self-archiving of e-prints in $\mathrm{OA}$ journals which makes them available on the Internet as pre-prints or post-prints [94]. The generic pre-print is an article submitted to a scholarly journal (or intended to be) for peer review and editorial approval. This term also commonly refers to papers submitted to series without peer review as well as articles not submitted to series. On the other hand, a post-print is the final version of an article that represents the changes made after the peer review and editorial processes. This can be either a new publisher version or a writer-updated pre-print to match the publisher's changes. E-prints are principally made available as (i) a personal website for the author, (ii) a disciplinary archive containing authors' work on one or more topics worldwide, (iii) an institutional e-print database containing e-prints from writers in a particular educational institution such as departments or organizations as a whole, or (iv) an academic repository of different types of digital work like data sets, online theses, and presentations and technical reports by authors at an institution, including e-prints [95].
There exists a broad range of free open-source codes available to support online libraries and corporate repositories. With e-prints being based on copyright law, business vendors have started providing turn-key systems to support the latter. Whether the author or publisher, the copyright holders of work must allow for OA. It should however be noted that there is no need for OA to change the existing copyright laws. Historically, publishers have also permitted writers to be given newspaper articles. Nevertheless, writers also retained the pre-print rights created for the final published book before the transfer of copyright, which allows them to make those pre-prints available to the public. Owing to this, some publishers refused to publish articles if they were eligible for digital pre-printing but it seems this practice is dying out [96]. Publishers are increasingly open to permitting writers to preserve copyright, with authors giving publishers specific rights, largely as a result of the OA movement. While many publishers need to transfer copyright, most of them now have clear policies that give publishers exclusive rights of distribution and allow other uses for their posts [97].

\subsubsection{Development of User-Friendly Digital Library Discovery} Systems. Developed DL discovery systems are created using technologies that enable library users to simultaneously search for multiple web-based resources and produce accessible search results. The present development was completed through an open-source software named Blacklight with features that include organization and indexing, advanced searching, ranking and sorting, enhanced services, enhanced displayed, personal information environment, and support/integration with social networking tools [82]. The advantage of this software is that it is used by libraries to create discovery layers or institutional repositories to improve and update available technical frameworks to suit new digital materials [98]. Blacklight was first developed at the University of Virginia based on a Ruby on Rail programming framework and Apache SOLR indexing, search, and retrieval technology [99]. It also provides a flexible toolkit for a broad variety of record types and is the principal search interface to the hydra project digital asset management.

The technological tools used for the creation of this DL discovery system contents were (i) Ruby 2.2.2, (ii) Rails 5.1, and (iii) Solr open-source search platform, written in Java. Blacklight has several plugins. For instance, Blacklight MARC is library catalog enhancements, a spotlight that enables librarians, and curators, to create attractive, featurerich websites highlighting these collections, and GeoBlacklight is a multi-institutional open-source collaboration that builds a better way to find and share geospatial information [99]. In the present development, the DL discovery system features were grouped into three categories, namely, (i) large search space, a search can find the data from various data sources; (ii) intuitive usability, like a search engine, simple form with advanced search functions; and (iii) ranking of the results by relevance, the "best" hit is shown first, not necessarily the newest hit. Figure 3 shows 


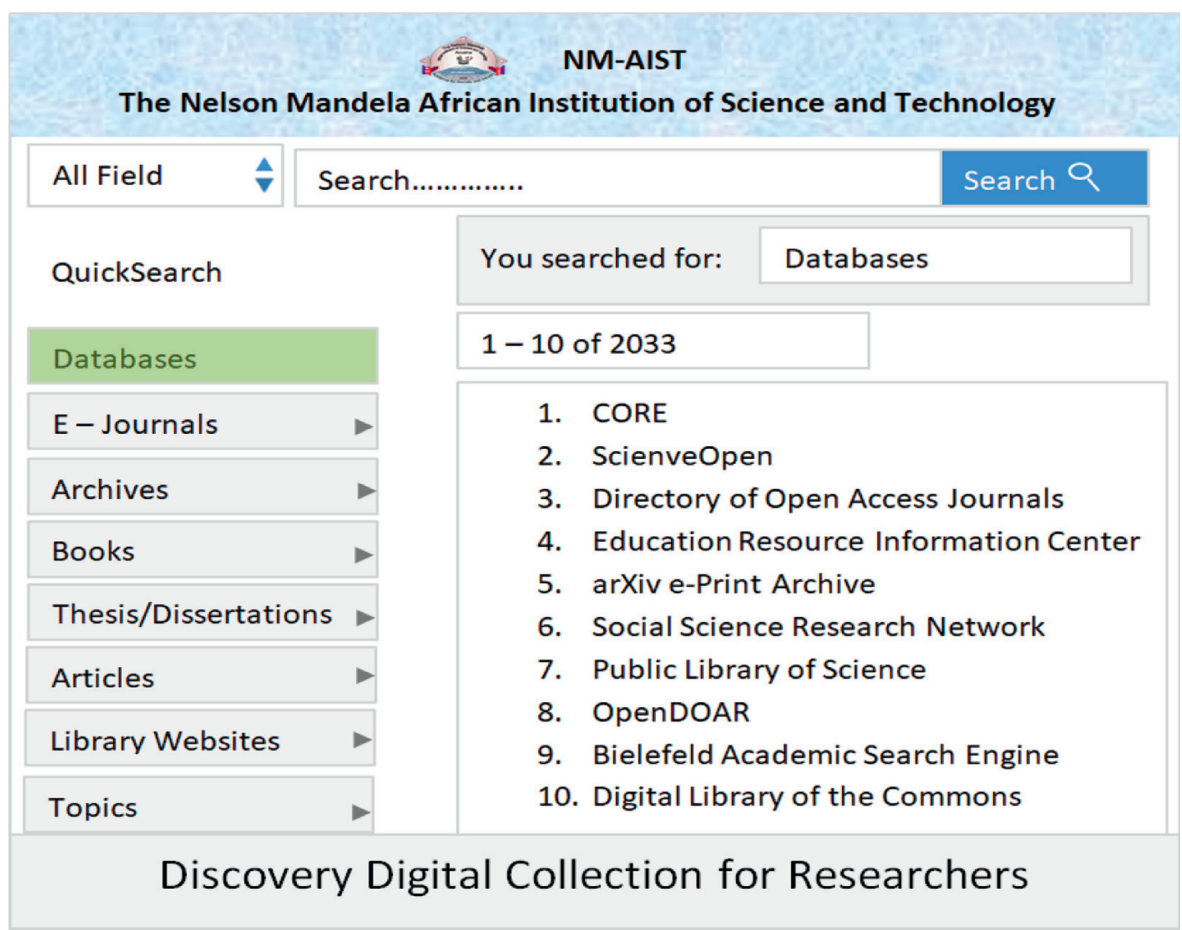

FIGURE 3: User-friendly digital library discovery system developed.

the developed user-friendly DL discovery system as a result of this review work.

The developed user-friendly DL discovery systems features could further be described as follows: (i) a discovery interface that provides access to several of resources availed by the library in a single-search window. Although this has many definitions in literature, there is an enhancement on specific major features like the central index that represents the metadata, and the full-text content is converted into a single index, the single-search box, relevancy-ranking, and facets. (ii) An end-user interface is the static HTML web page designed for searching using a web browser to provide access to the library-availed resources. The end-user interface provides access to a simple yet advanced search-box where the question is executed when the user enters the search expression. The advanced query lets the user search according to available conditions and the output is typically a short or full record display format depending on user preference. (iii) Inter-operability with a link-resolver which provides a link to the full-text from a citation record in the search results. (iv) Local search and retrieval which are generally achieved by integrated indexing, search, and retrieval to the collection of interest. Many local search and retrieval indices use Apache SOLRTM [79] or [100] as the local search tool. (v) The capacity to synergistically communicate with the ILS implementations of the library. This being the most critical feature, the library discovery system should show the status of items in the library's physical collection, order for holds or recalls, interact with the patron records to display account status, list charged items, fines or fees due, and view/update personal details. (vi) Access to a remote index platform via Application Programming
Interface (API) alongside or instead of search queries to receive results from a local index. A discovery index can also link to the external platform that indexes contents of interest. This kind of inter-operability is made possible by the API, a common agreement between the content and the discovery service providers which manages requests and responses, records transfers, and presents documentation to back a search session [101].

\section{The Way Forward and Future Prospects}

Using ICT has revolutionized how the worldwide community uses information. Library members are no longer limited to online tools designed to meet their information needs despite the challenges faced by scholars and the research communities when accessing online information. Some of these problems include difficulty in access, download exceptions and restrictions, complex interface design of information systems, low quality of the communication process, and poor quality of the Internet. Taking into account the need for information, it is now that electronic library resources with multitasking information accessible, simple interface design, quality assurance service, and ease of communication via a social network have been developed and implemented to satisfy DL users.

There still exist some limitations that accompany library discovery systems. Despite the strength and the relative easeof-use of these tools, the cooperation of all content providers in sharing their contents is key to enabling full access to a discovery tool. At times, some of the databases may fail to work with some discovery tools. In such a case, researchers should be notified and be advised to perform a database 
search. Another main problem is that a lot of databases, to enable subject access to material on their site, make use of their specialized vocabularies. Since a discovery tool in essence combines several databases into one, researchers must know that databases might describe certain topics differently. For instance, the term "imagery" can be used differently in literature and psychology databases. Thus, researchers should use better descriptions while searching for articles to reduce mismatches that are likely to occur in a discipline. This is unlike Google which does searching in full content and rather than in metadata as in the library discovery system. This makes it difficult to achieve search effectiveness in the library discovery system [79]. Based on these observations, this review provides a systematic analysis of DL information accessibility in the following aspects: (i) analyzes the barriers preventing learners from using online library resources, (ii) examines users' satisfaction with digital libraries, (iii) studies essential variables related to DL adoption and usage, and (iv) describes the next generation in DL services and finally develops userfriendly DL discovery systems to mitigate distance learners' technical hitches.

\section{Conclusions}

This review intended to provide a systematic analysis of DL information accessibility and the development of a userfriendly DL discovery system. The analysis shows that the library user's dimension plays the most significant role in DL systems improvement. This allows researchers to identify what aspects could be inherited from the other technologies specifically for the DL system enhancement. This analysis describes the different DL systems and models, DL tools, and the proposed design of library digital services, and finally has developed a user-friendly DL discovery system. The developed DL discovery system considers how to provide their patrons with QoS. In the developed DL discovery system, some components have been highlighted that are concerned with providing environmental quality, delivery quality, outcome quality, and standard with DL procedures. This work contributes to the conceptual design and development of the discovery tool in the university libraries concerning the transition from normal DL resources to modern DL resources. It also offers in-depth user forecasts and instruction on the management of library tools for references and information processing. Nonetheless, most libraries are now starting to introduce one-stop shopping programs for their customers, where at the same time several different types of resources are being queried. Additionally, this work offers widely library user awareness, adoption, and usage of DL resources in which the use of DL discovery systems' development tools is distinct from the use of other library services such as the online catalog and the repositories.

\section{Data Availability}

The studied data used to support the findings of this study are included within the article.

\section{Conflicts of Interest}

All authors declare that they have no conflicts of interest.

\section{Acknowledgments}

This work was partly sponsored by the German Academic Exchange Service (DAAD) and supported by The Nelson Mandela African Institute of Science and Technology. The authors gratefully acknowledge the assistance of librarians from the various institutions involved in library digitization initiatives who provided valuable information and ongoing support in writing this article with the development of a user-friendly DL discovery system.

\section{References}

[1] M. K. Sinha and A. Deb, "Usage of E-resources available under INDEST-AICTE consortium by library users of NIT, Silchar, Assam," in Proceedings of the 2015 4th International Symposium on Emerging Trends and Technologies in Libraries and Information Services, ETTLIS 2015, pp. 191-198, Noida, India, January 2015.

[2] M. K. Sinha, G. Singha, and B. Sinha, "Usage of electronic resources available under UGC-INFONET digital library consortium by Assam university library users," in Proceedings of the 8th International CALIBER, 2011, Goa, India, March 2011.

[3] S. C. Eze, V. C. Chinedu-Eze, and A. O. Bello, "The utilisation of E-learning facilities in the educational delivery system of Nigeria: a study of M-university," International Journal of Educational Technology in Higher Education, vol. 15, no. 1, 2018.

[4] P. T. C. d. O. Salvador, M. D. S. Bezerril, C. M. S. Mariz, M. I. D. Fernande, J. C. A. Martins, and V. E. P. Santos, "Virtual learning object and environment: a concept analysis," Revista Brasileira de Enfermagem, vol. 70, no. 3, pp. 572-579, 2017.

[5] D. Dukić and J. Strišković, "Croatian university students' use and perception of electronic resources," Library and Information Science Research, vol. 37, no. 3, pp. 244-253, 2015.

[6] A. Jose, "Evaluation of digital libraries: a case study," in Proceedings of the International Conference of Semantic Web \& Digital Libraries, Kobe, Japan, October 2007.

[7] M. Sitnicki, "Development of a model of digital research universities," Baltic Journal of Economic Studies, vol. 4, no. 1, pp. 311-318, 2018.

[8] I. O. Agboola, "Use of print and electronic resources by agricultural science students in Nigerian universities," $L i$ brary \& Information Science Research, vol. 32, no. 1, pp. 62-65, 2010.

[9] M. Stephen, Mudogo, and M. Stephen, "The electronic library status of digital heritage preservation management in eastern Africa status of digital heritage preservation management in eastern Africa," The Electronic Library Collection Building Iss Aslib Proceedings, vol. 32, no. 3, 2014.

[10] M. Koivunen and K. Saranto, "Nursing professionals' experiences of the facilitators and barriers to the use of telehealth applications: a systematic review of qualitative studies," Scandinavian Journal of Caring Sciences, vol. 32, no. 1, pp. 24-44, 2018.

[11] A. G. Larson and M. Owusu-Acheaw, "Information needs of distance learners: a case of Winneba study center, University 
of Education, Winneba, Ghana," Turkish Online Journal of Distance Education, vol. 17, no. 3, 2016.

[12] E. Matheus and A. Ruth, "Learners' perceptions on online library resources at Namibian college of open learning," Information And Learning Science, vol. 119, no. 9-10, pp. 597-606, 2018.

[13] M. N. Masrek and J. E. Gaskin, "Assessing users satisfaction with web digital library: the case of universiti teknologi MARA," The International Journal of Information and Learning Technology, vol. 33, no. 1, pp. 36-56, 2016.

[14] J. A. Adams and S. C. Bonk, "Electronic information technologies and resources: use by university faculty and faculty preferences for related library services," College \& Research Libraries, vol. 56, no. 2, pp. 119-131, 2014.

[15] J. Y. Hwang, J. Kim, B. Lee, and J. H. Kim, "Usage patterns and perception toward E-books: experiences from academic libraries in South Korea," Electronic Library, vol. 32, no. 4, pp. 522-541, 2014.

[16] D. Jotwani, "Library resources and services in Indian institutes of technology," Annals of Library and Information Studies, vol. 60, no. 3, pp. 204-211, 2013.

[17] A. Rubel, "Libraries, electronic resources, and privacy: the case for positive intellectual freedom," The Library Quarterly, vol. 84, no. 2, pp. 183-208, 2014.

[18] W. Hong, J. Y. L. Thong, W. M. Wong, and K. Y. Tam, "Determinants of user acceptance of digital libraries: an empirical examination of individual differences and system characteristics," Journal of Management Information Systems, vol. 18, no. 3, pp. 97-124, 2001.

[19] D. Agaba, I. M. N. Kigogo-Bukenya, and J. B. Nyumba, "Utilization of electronic information resources by academic staff at Makerere university," University of Dar Es Salaam Library Journal, vol. 6, no. 1, 2011.

[20] M. Ahmad and J. H. Abawajy, "Digital library service quality assessment model," Procedia-Social and Behavioral Sciences, vol. 129, pp. 571-580, 2014.

[21] W. H. DeLone and E. R. McLean, "Measuring E-commerce success: applying the DeLone \& McLean information systems success model," International Journal of Electronic Commerce, vol. 9, no. 1, p. 31, 2004.

[22] B. H. Wixom and P. A. Todd, "A theoretical integration of user satisfaction and technology acceptance," Information Systems Research, vol. 3, pp. 1-29, 2005.

[23] Z. Zhang, "Feeling the sense of community in social networking usage," IEEE Transactions on Engineering Management, vol. 57, no. 2, pp. 225-239, 2010.

[24] Y. F. Tu and G. J. Hwang, "The roles of sensing technologies and learning strategies in library-associated mobile learning: a review of 2007-2016 journal publications," International Journal of Mobile Learning and Organisation, vol. 12, no. 1, p. $42,2018$.

[25] R. Guajardo, K. Brett, and F. Young, "The evolution of discovery systems in academic libraries: a case study at the university of Houston libraries," Journal of Electronic Resources Librarianship, vol. 29, no. 1, pp. 16-23, 2017.

[26] K. E. Oh and M. Colón-Aguirre, "A comparative study of perceptions and use of Google scholar and academic library discovery systems," College And Research Libraries, vol. 80, no. 6, pp. 876-891, 2019.

[27] D. Ojakaa, R. Benard, and F. Dulle, CSOs HSS Support Proposal, World Health Organization, Geneva, Switzerland, 2014.
[28] E. Mączyńska, "The economy of excess versus doctrine of quality," Kwartalnik Nauk o Przedsiębiorstwie, vol. 42, no. 1, pp. 9-15, 2017.

[29] A. Balog, "Testing a multidimensional and hierarchical quality assessment model for digital libraries," Studies in Informatics and Control, vol. 20, no. 3, 2011.

[30] J. Jeng, "What is usability in the context of the digital library and how can it be measured," Information Technology and Libraries, vol. 24, no. 2, p. 47, 2013.

[31] M. N. Gaskin, A. Jamaludin, and S. A. Mukhtar, "Evaluating academic library portal effectiveness: a Malaysian case study," Library Review, vol. 59, no. 3, pp. 198-212, 2010.

[32] M. H. Vinagre, L. G. Pinto, and P. Ochôa, "Revisiting digital libraries quality: a multiple-item scale approach," Performance Measurement and Metrics, vol. 12, no. 3, pp. 214-236, 2011.

[33] M. Kyrillidou and S. Giersch, "Developing the DigiQUAL protocol for digital library evaluation," in Proceedings of the 5th ACM/IEEE-CS Joint Conference on Digital Libraries (JCDL'05), Denver, CO, USA, June 2005.

[34] F. D. Davis, "Perceived usefulness, perceived ease of use, and user acceptance of information technology," MIS Quarterly, vol. 13, no. 3, p. 319, 1989.

[35] R. Hussein, N. S. A. Karim, and M. Hasan Selamat, "The impact of technological factors on information systems success in the electronic-government context," Business Process Management Journal, vol. 13, no. 5, pp. 613-627, 2007.

[36] G. T. Lee, N. Dahlan, T. Ramayah, N. Karia, M. Hasmi Abu, and A. Hassan, "Impact of interface characteristics on digital libraries usage," Malaysian Online Journal of Instructional Technology, vol. 2, no. 1, 2005.

[37] T. Ramayah and J. W. C. Lee, "System characteristics, satisfaction and E-learning usage: a structural equation model (SEM)," Turkish Online Journal of Educational Technology, vol. 11, no. 2, pp. 196-206, 2012.

[38] J. Y. L. Thong, W. Hong, and K. Y. Tam, "Understanding user acceptance of digital libraries: what are the roles of interface characteristics, organizational context, and individual differences?" International Journal of Human Computer Studies, vol. 57, no. 3, pp. 215-242, 2002.

[39] E. T. Lwoga, "Measuring the success of library 2.0 technologies in the African context: the suitability of the DeLone and McLean's model," Campus-Wide Information Systems, vol. 30, no. 4, pp. 288-307, 2013.

[40] J. C. Roca, C. M. Chiu, and F. J. Martínez, "Understanding E-learning continuance intention: an extension of the technology acceptance model," International Journal of Human Computer Studies, vol. 64, no. 8, pp. 683-696, 2006.

[41] M. Kuźma and A. Mościcka, "Accessibility evaluation of topographic maps in the national library of Poland," $A b$ stracts of the ICA, vol. 1, 2019.

[42] H. Jeong, "An investigation of user perceptions and behavioral intentions towards the E-library," Library Collections, Acquisition and Technical Services, vol. 35, no. 2-3, pp. 45-60, 2011.

[43] F. Xu and J. T. Du, "Factors influencing users' satisfaction and loyalty to digital libraries in Chinese universities," Computers in Human Behavior, vol. 83, pp. 64-72, 2018.

[44] R. Agarwal, V. Sambamurthy, and R. M. Stair, "Cognitive absorption and the adoption of new information technologies," Academy of Management Proceedings, vol. 1997, no. 1, pp. 293-297, 1997. 
[45] J. J. Esposito, K. Walker, and E. Terry, "PDA and the university press," Journal of Scholarly Publishing, vol. 44, no. 3, pp. s1-s62, 2013.

[46] R. Anderson, "What patron-driven acquisition (PDA) does and doesn't mean: an FAQ-the scholarly kitchen," 2011.

[47] R. Anderson, "Patron-driven acquisitions: history and best practices," Library Review, vol. 61, no. 6, pp. 473-475, 2012.

[48] E. R. Lorbeer, "A demand-driven future," Against the Grain, vol. 25, no. 2, 2016.

[49] M. B. Schell, "Health sciences collection management for the twenty-first century, by Susan K. Kendall," Medical Reference Services Quarterly, vol. 37, no. 4, pp. 434-435, 2018.

[50] J. Coghill, "Patron-driven acquisition (PDA)," Journal of Electronic Resources in Medical Libraries, vol. 16, no. 1, pp. 25-27, 2019.

[51] Y. H. Chen and I. Chengalur-Smith, "Factors influencing students' use of a library web portal: applying course-integrated information literacy instruction as an intervention," Internet and Higher Education, vol. 26, pp. 42-55, 2015.

[52] S. Joo and N. Choi, "Understanding users' continuance intention to use online library resources based on an extended expectation-confirmation model," Electronic Library, vol. 34 , no. 4 , pp. 554-571, 2016

[53] L. A. Gojeh, L. Ishaya Dutse, and H. Daudu, "Human and physical environmental factors affecting students' utilization of library and information services in colleges of education libraries in Nigeria," American International Journal of Research in Humanities, Arts and Social Science, 2013.

[54] C. P. Hu, Y. Hu, and W. W. Yan, "An empirical study of factors influencing user perception of university digital libraries in China," Library and Information Science Research, vol. 36, no. 3-4, pp. 225-233, 2014.

[55] V. A. Thurmond, H. R. Connors, B. B. Frey, and K. Wambach, "Evaluation of student satisfaction: determining the impact of a web-based environment by controlling for student characteristics," American Journal of Distance Education, vol. 16, no. 3, pp. 169-190, 2002.

[56] A. Isah and K. J. Bwalya, The Adoption and Usage of Digital Library Resources by Academic Staff in Nigerian Universities: A Case Study of University of Ilorin, Digital Libraries, London, UK, 2014.

[57] W. Yan, S. Deng, and Y. Zhang, "Factors influencing the intention to use information service mashups: an empirical study of digital libraries in China," Electronic Library, vol. 34, no. 4, pp. 696-716, 2016.

[58] I. Xie and K. K. Matusiak, "User needs and search behaviors," Discover Digital Libraries, pp. 231-253, 2016.

[59] C. M. Owusu-Ansah, A. Rodrigues, and T. Van Der Walt, "Factors influencing the use of digital libraries in distance education in Ghana," Libri, vol. 68, no. 2, pp. 125-135, 2018.

[60] H. K. Koshali, M. S. Allahyari, M. Chizari, and Z. D. Masouleh, "Factors influencing on acceptance of digital library by faculty members of agricultural educational and research institutions in Guilan province," Iranian Journal of Agricultural Economics and Development Research (IJAEDR), vol. 46, no. 2, pp. 335-346, 2015.

[61] B. Ju and D. Albertson, "Exploring factors influencing acceptance and use of video digital libraries," Information Research: An International Electronic Journal, vol. 23, no. 2, 2018.

[62] M. R. A. Kadir, R. Ab Ghani, A. Abu Bakar, Ap A. Bunawan, and M. R. Seman, "Factors influencing users satisfaction using electronic resources," in Proceedings of the 27th International Business Information Management Association Conference, Innovation Management and Education
Excellence Vision 2020: from Regional Development Sustainability to Global Economic Growth, IBIMA 2016, Milan, Italy, May 2016.

[63] W. P. Mtega, F. Dulle, A. W, Malekani, and A. Chailla, “The usage of E-resources among agricultural researchers and extension staff in Tanzania," Library and Information Research, vol. 38, no. 119, pp. 47-66, 2015.

[64] N. Parsazadeh, N. M. M. Zainuddin, R. Ali, and A. Hematian, "A review on the success factors of E-learning," in Proceedings of the Second International Conference on E-Technologies and Networks for Development (ICeND2013), pp. 42-49, Kuala Lumpur, Malaysia, March 2013.

[65] G. A. Torres-Vargas and A. Georgina, "The design of a digital library for Mexican universities," Procedia-Social and Behavioral Sciences, vol. 73, pp. 751-756, 2013.

[66] B. Gunjal, "Discovery tools and services for libraries: issues and challenges," in Proceedings of the 36th Annual International Association of University Libraries Conference (IATUL 2015), Hannover, Germany, July 2015.

[67] D. G. Luenberger, "Information science," Oxford University Press, Oxford, UK, 2012.

[68] A. S. Evmenova and R. Kelley, "Supporting the writing process with technology for students with disabilities," Intervention in School and Clinic, vol. 55, no. 2, pp. 78-85, 2019.

[69] C. Wimmer, C. Stancu, P. Hofer et al., "Initialize once, start fast: application initialization at build time," Proceedings of the ACM on Programming Languages, 2019.

[70] Z. Raza, K. Mahmood, and N. F. Warraich, "Application of linked data technologies in digital libraries: a review of literature," Library Hi Tech News, vol. 36, no. 3, pp. 9-12, 2019.

[71] M. Tripathi and V. K. J. Jeevan, "Quality assurance in distance learning libraries," Quality Assurance in Education, vol. 17, no. 1, pp. 45-60, 2009.

[72] P. Joore and H. Brezet, "Online library: digital copies," BMJ Open, 2016.

[73] D. L. Ferullo, "Major copyright issues in academic libraries: legal implications of a digital environment," in The Changing Landscape for Electronic Resources: Content, Access, Delivery, and Legal Issues, Taylor \& Francis, Oxfordshire, UK, 2013.

[74] G. Mahesh and R. Mittal, "Digital content creation and copyright issues," Electronic Library, vol. 27, no. 4, pp. 676-683, 2009.

[75] G. Cleveland, "Digital libraries: definitions, issues and challenges (occasional paper, IFLA UDT core program)," 2008.

[76] D. Wells, "Library discovery systems and their users: a case study from curtin university library," Australian Academic and Research Libraries, vol. 47, no. 2, pp. 92-105, 2016.

[77] V. Spezi, C. Creaser, A. O'Brien, and A. Conyers, Impact of Library Discovery Technologies A Report for UKSG, Loughbough University, Loughborough, UK, 2013.

[78] S. K. Pal, "Library resources discovery service: future of the libraries," in Proceedings of the 62nd ILA Conference 2017, Karnataka, India, February 2017.

[79] S. S. Chetan, "Library discovery system: an integrated approach to resource discovery," Informatics Studies, vol. 4, no. 3, pp. 27-38, 2017.

[80] A. Kabashi, C. Peterson, and Tim Prather, "An executive summary of 'discovery services: a white paper for the Texas state library \& archives commission', Texas Library Journal, vol. 90, no. 4, pp. 10-12, 2014.

[81] P. Sarkar and P. Mukhopadhyay, "Full-text ETD retrieval in library discovery system: designing a framework," Annals of 
Library and Information Studies, vol. 63, no. 4, pp. 274-288, 2016.

[82] B. K. Roy, S. C. Biswas, and P. Mukhopadhyay, "Designing webscale discovery systems using the VuFind open source software," Library Hi Tech News, vol. 35, no. 3, pp. 16-22, 2018.

[83] S. K. Pal, "Library resources discovery service: future of the libraries," SSRN Electronic Journal, 2020.

[84] W. M. Beyene and M. Ferati, "A case for adaptation to enhance usability and accessibility of library resource discovery tools," in Lecture Notes in Computer Science (including Subseries Lecture Notes in Artificial Intelligence and Lecture Notes in Bioinformatics)Springer, Berlin, Germany, 2017.

[85] F. W. Chickering and S. Q. Yang, "Evaluation and comparison of discovery tools: an update," Information Technology and Libraries, vol. 33, no. 2, p. 5, 2014.

[86] W. M. Beyene, "Resource discovery and universal access: understanding enablers and barriers from the user perspective," Studies in Health Technology and Informatics, vol. 229, pp. 556-566, 2016.

[87] K. Wilson, N. Cameron, L. Montgomery, and C. K. K. Huang, "Access to academic libraries: an indicator of openness?” Information Research, vol. 24, no. 1, 2019.

[88] H. Piwowar, J. Priem, V. Larivière et al., "The state of OA: a large-scale analysis of the prevalence and impact of open access articles," PeerJ, vol. 13, no. 6, Article ID e4375, 2018.

[89] UNESCO, "Introduction to open access (open access for library schools)," UNESCO, Paris, UK, 2015.

[90] K. L. Palmer, E. Dill, and C. Christie, "Where there's a will there's a way?: survey of academic librarian attitudes about open access," College and Research Libraries, vol. 70, no. 4, pp. 315-335, 2009.

[91] O. Bolarinwa and S. C. A. Utulu, "Open access: perceptions and reactions of academic librarians in Nigerian private universities," African Journal of Library Archives and Information Science, vol. 21, no. 2, pp. 127-137, 2011.

[92] E. T. Lwoga and F. Questier, "Open access behaviours and perceptions of health sciences faculty and roles of information professionals," Health Information and Libraries Journal, vol. 32, no. 1, pp. 37-49, 2015.

[93] E. M. Sanjeeva and S. C. Powdwal, "Open access initiatives: reframing the role of librarians," Library Herald, vol. 55, no. 4, p. 467, 2017.

[94] H. R. Jamali, "Copyright compliance and infringement in researchgate full-text journal articles," Scientometrics, vol. 112, no. 1, pp. 241-254, 2017.

[95] P. Mapulanga, "Digitising library resources and building digital repositories in the university of Malawi libraries," Electronic Library, vol. 31, no. 5, pp. 635-647, 2013.

[96] K. Moskalenko, "The right of publicity in the USA, the EU, and Ukraine," International Comparative Jurisprudence, vol. 1, no. 2, pp. 113-120, 2015.

[97] C. W. Bailey Jr., "Open access in libraries," Library Student Journal, 2006.

[98] S. Popowich, "Agile open-source discovery: blacklight with EBSCO discovery service," in Exploring Discovery: The Front Door To Your Library's Licensed and Digitized Content, American Library Association, Chicago, IL, USA, 2016.

[99] E. Sadler, "Project blacklight: a next generation library catalog at a first generation university," Library Hi Tech, vol. 27, no. 1, pp. 57-67, 2009.

[100] Elastic, "Kibana: explore, visualize, discover data," 2019.

[101] T. Adamich, "Metadata and the next generation library catalog: will the catalog become a true discovery system?" Technicalities, vol. 30, no. 3, pp. 12-15, 2010. 